the success of the experiment with the elastic band depends upon the band being of a certain thickness, and upon the weights being so adjusted as to balance without overbalancing its elasticity. Failing these conditions charge and discharge may not tell in causing elongation and contraction. And, therefore, the absence of perceptible elongation and contraction in the nerve-fibre under the charge and discharge may be simply owing to the fact that the thickness and stretching of the neurilemma have not been adjusted for the production of these results. Besides, it is by no means certain that there are not in some nerve-fibres slight changes which are strictly parallel to the elongation and contraction witnessed in muscular fibres.

In a word, there seems to be good reason for believing that in nerve as in muscle electricity may have to do much of what is commonly regarded as the special work of an inherent vital principle.

4. How in maintaining the "tone of the system" electricity may have to do much of what is commonly regarded as the special work of a vital principle.

After what has been said little remains to be added under this head. The conclusion arrived at is that each perfect fibre and cell of living muscle and nerve (and, by implication, every living fibre and cell), is a charged leyden-jar while at rest. It is that the membranous portion of the fibre or cell is at this time compressed by the mutual attraction of the two opposite charges disposed leyden-jar-wise upon its two surfaces. It is that the effect of this compression is to elongate the fibre or cell by squeezing out this membrane lengthwise. What then? May it be that this compression, this squeezing out, is sufficient to account for what is called the "tone of the system"? This state, no doubt, is indefinite enough, but it becomes more definite when viewed in this wayso definite, in fact, that here also, in the maintenance of the "tone of the system" that is to say, electricity may have to do much of what is commonly believed to be the work of a vital principle.

5. How in certain processes of growth electricity may co much of what is commonly regarded as the special work of a vital principle.

A cell or fibre is at first a mass of protoplasm without any investing membrane. Later, this membrane makes its appearance, and how is this? Is it that the surface of the protoplasmic mass, except at the part or parts where the nucleus is afterwards met with, hardens by desiccating, or dying, or changing in some other way, and, so hardening, acquires dielectric properties? Is it that the molecular changes ever going on in the protoplasmic matter beneath this crust, develope a charge on the inside of this crust, which, acting inductively, leads to the development of the opposite charge on the outside? Is it that the compression arising from the mutual attraction. of these opposite charges, causes the crust to stretch out every way, and so separate from the underlying protoplasmic mass, leaving thereby in some instances a vacuole, which may be filled with a thin liquid or even air? Is this the way in which the sarcolemma and neurilemma, the cell-walls, and all membranes more or less analogous to them, may be formed? After what has been said such an idea is by no means improbable. Nay, such an idea may be looked upon as the natural consequence of the premises. And if so, then electricity may have to do much of what is commonly believed to be the work of a vital principle in these phenomena of growth, as well as in the various processes which have been already passed in review, and upon which so much has been said as to leave only room now for these bare hints of what might be said upon the subject.

C. B RADCIIFFE

\section{MERCURY PHOTOGRAPHS}

$A \mathrm{~N}$ entirely novel method of photographic printing has just been discovered by M. Merget of Lyons. Although akin in some respects to the daguerreotype process, it differs essentially therefrom in the fact that exposure to light is not necessary to the formation of every separate image. It is difficult indeed just now to apply any distinguishing name to M. Merget's invention, for the methods hitherto discovered-and the number of these has, we all know, increased of late beyond all calculation - are all of them divisible into two very distinct classes. Thus we have those processes broadly termed chemical, in which every print is secured by the aid of light, as for instance, the nitrate of silver and carbon methods; and those again where a matrix, or printing block, having been prepared, the copies are struck off in the ordinary lithographic or printing press; photographs prepared in this latter manner are usually termed photo mechanieal prints. M. Merget's invention partakes singularly enough of the nature of both classes ; for while the prints are undoubtedly formed by chemical action, the question of light is of no mornent at all, and the manipulations involved are to some extent of a mechanical nature.

The experiments of Faraday upon the diffusion of gases will be remembered by many, and it was the results arrived at by that distinguished philosopher that incited M. Merget, the Professor of Physics at the Faculté des Sciences of Lyons, to take up the investigation he has so successfully carried through. Faraday had already found out that the vapour of mercury acted very sensibly upon gold-leaf, and the first task undertaken by M. Merget was to discover whether this same action also took place upon other metals or their compounds. The investigation, it should be stated, was designed to be of a purely theoretical nature, and was not undertaken, in the first instance at any rate, with a view of working out any practical processes such as may eventually result from the research. The principal points discovered by $M$. Merget may be thus summarised :-

$\mathrm{I}$. The vaporisation of mercury is a continuous phenomenon; that is to say, the metal emits vapour at all times, even at a very low temperature, and when in a solidified form.

2. Mercury vapour may be condensed upon certain substances, such as carbon, platinum, \&c., without these latter being chemically affected.

3. Mercury vapour will pass with exceeding facility through porous bodies, such as wood, porcelain, \&c.

4. The salts of all precious metals when in solution are very sensitive to the action of mercury vapour, which has the effect of rapidly reducing them.

The most sensitive to mercury of the precious metal salts are nitrate of silver and the soluble chlorides of gold, palladium, and iridium, and paper prepared with any of these forms at once a most delicate test for the volatile metal; but the solutions must contain some hygrometric body to prevent complete desiccation, so that the surface coated with them will always remain in a moist condition. To demonstrate how exceedingly sensitive this test-paper is to mercury, we may state that its contact with any body containing but a slight trace of amalgam suffices to darken the surface, while it is affirmed that any workman who has been employed for some time in a looking.glass or other similar factory, may produce an impression of his hand by simply laying the same upon a sensitive surface of this kind, the minute traces of mercury in the pores of the skin being amply sufficient to bring about a reduction of the salt, and to produce consequently an imprint of the fingers. In the same way a section of wood exposed to mercury vapours, and afterwards pressed in contact with a sheet of sensitive paper, prints off upon the surface all the rings and markings it possesses, the mercury being deposited in the pores of the wood in a more or less condensed form. 
In the event of nitrate of silver being used for preparing the paptr, it is necessary, obviously, to exclude the light, as otherwise a reducing action will be already set up by solar means alone, but with the salts of palladium or platinum no such action need be feared. According to the kind of metallic salt employed, so the tint of the impression varies, but in most cases an intense black may be obtained where the action has proceeded far enough.

Having described M. Merget's discoveries thus far, it is easy to guess how that gentleman employs them in the carrying out of a photographic process. An ordinary glass negative, possessing an image which has been formed by the deposition of silver particles, is prepared in a suitable manner to protect it from injury by contact with the mercury (such, for instance, as coating it in some way with platinum or carbon particles), and the picture is then exposed to the action of mercury vapour. The vapour condenses, in a more or less concentrated form, upon the image-in the same way, pretty well, as it becomes deposited upon, and develops, the latent image in the daguerreotype process-and subsequently the plate thus treated is brought into contact with the sensitive paper. The consequence is that the minute particles of mercury deposited all over the image exercise a reducing action upon the salis on the surface of the paper, and a print results of the original piotosraph, possessing the same gradation of tint as the original. Indeed, when nitrate of silver is employed for sensitising the paper, the photograph secured is in every respect similar to that produced by light in the ordinary silver printing process, and the picture is forthwith toned and fixed in the same way, in fact, as one of these; in the one case, however, the reduction of the silver salts has been brought about by mercury vapour, while in the other light alone has been the reducing agent. Impressions obtained by means of platinum and palladium salts need simply to be washed in water in order that they may be permanently fixed. These latter, in truth, are so indestructible and inalterable that they cannot be destroyed except by a chemical agent which would at the same time radically injure the paper, or other basis, upon which they rest.

This process of photography is not yet in such an advanced state as to be of any practical importance; but, nevertheless, it is certainly one of the most ingenious and interesting discoveries made of late in this branch of Science. The great advantage it possesses is that of printing without the aid of light, and yet producing prints with detail and half-tone dependent upon delicate chemical reaction-such rare gradation being secured as our present light-printed pictures (silver and carbon prints) alone possess. A mechanical printing process could, of course, easily be worked out from these data, if considered desirable ; and, indeed, it is by no means improbable that this will be the most successful way of applying the discoveries in a practical form. But even in the event of no practical use at all being made of the process--tor this is indeed questionable-the research, regarded from a purely scientific point of view, is deserving of the highest eulogium.

\section{H. BADEN PRITCHARD}

\section{NOTES}

IN another column will be found full details of the observations of the Total Eclipse of December 12, made at Bekul, by Mr. Norman Lockyer and Captain Maclear. In future numbers we hope to give similar reports from the observers at the other stations. The weather was very favourable at all the stations, with only one exception.

M. JANSSEN writes as follows to the French Academy of Sciences, under date Sholoor, Neelgherry, I2th of December, I87 I, to A.M. :- "I have just observed the eclipse, only a few moments since, with an admirable sky, and whilst still under the emotion caused by the splendid phenomenon of which $I$ have just been a witness, I address a few lines to you by the Bombay courier, who is to start instantly. The result of my obsurvations at Sholoor indicates without any doabt the solar origin of the corona, and the existence of matter beyond the chromosphere."' And in a letter to M. Faye, written half an hour later, he says:"I have just seen the corona, as it was impossible for me to do in 1868 , when I was entirely occupied with the spectrum of the protuberances. Nothing can be finer, nothing more luminoue, with peculiar forms which exclude all possibility of a terrestrial atmospheric origin. The spectrum contains a very remarkable brilliant green line already indicated; it is not continuous, as has been asserced, and $\mathrm{I}$ have found in it indications of the obscure lines of the solar spectrum (especially D). I believe the question whether the corona is due to the terrestrial atmosphere is settled, and we have before us the prospect of the study of the extra-solar regions, which will be very interesting and fertile."

PROF. HUXLex'S friends, and the scientific world generally, will leam with great regret that he has been compelled to relinquish all work for the present, his medical advisers having ordered him complete rest for two months, for which purpose he has just started for Egypt. There is every prospect that at the end of the time he will return to his old work with renewed vigour.

THE Regius Professorship of Physic in the University of Cambridge has becume vacant by the resignation of $D$. Bond, who has heid the office since 1851 .

THE Council of the College of Preceptors has arranged for the delivery of a series of three lectures to the members of the college and their friends, on the teachiag of science in secondary schools. The first lecture of the series, "On Teaching Physics," was delivered at the rooms of the College, 42, Queen Square, on Saturday evening, the I $^{\text {th }}$ instant, by Professor G. C. Foster, F.R.S. ; the secorid, "On Teaching Mechanics," was delivered yesterday (Wednesday) evening by Prof. W. G. Adams; and the third, "On Teaching Botany and Geology," is to be delivered on Monday evening, 22nd inst., by Mr. J. M. Wilson, of Rugby. The point mainly insisted on by Prof. Foster in his lecture, was the necessity, in order to make the study of Physics of much use as a training for the mind, that the pupils should not only see, but actually make ex. periments for themselves, so that the principal facts and phenomena discussed may be known to them as matters within their own experience.

A SERIES of lectures will be delivered in Gresham Col. lege, Basinghall Street, by Mr. E. Symes Thompson, M.D., F.R.C.P., as follows:-Thursday, January 18, 1872, On the Digestive Organs in Health and Disease (continued from last course) ; Friday, January 19, 1872, On the Blood Vessels; Satur. day, January 20,1872 , On the Pulse.

At the first Anniversary Meeting of the Anthropological Institute, held January 15, Sir John Lubbock, Bart., M.P., F.R.S., president, in the chair, the president delivered an address, and the officers and councils to serve for 1872 were elected as follows :-President-Sir John Lubbock, Bart., M.P., F.R.S. ; Vice-Presidents-Mr. W. Blackmore, Prof. Busk, F.R.S., Dr. Charnock, Mr. John Evans, F.R.S., Mr. George Harris, Prof. Huxley, F.R.S. ; Director-Mr. E. W. Brabrook ; TreasurerMr. J. W. Flower; Council-Mr. H. C. Bohn, Captain R. F. Burton, Mr. James Butler, Mr. A. Campbell, M.D., F.R.S., Mr. Hyde Clarke, Mr. J. Barnard Davis, M.D., Mr. Robert Dunn, Mr. David Forbes, F.R.S., Colonel A. Lane Fox, Mr. A. W. Franks, Sir Duncan Gibb, Bart., M.D., Mr. Joseph Kaines, Mr. Richard King, M.D., Mr. A. L. Lewis, Mr. Clements R. Markham, Captain Bedford Pim, R.N., Mr. F. G. Price, Mr. C. Robert des Ruffières, Mr. Spottiswoode, V.P.R.S., Mr. C. Staniland Wake. 